\title{
3D geomechanical modeling and estimating the compaction and subsidence of Fahlian reservoir formation (X-field in SW of Iran)
}

\author{
Ali Ranjbar ${ }^{1} \cdot$ Hossein Hassani ${ }^{2} \cdot$ Kourosh Shahriar $^{3}$
}

Received: 14 August 2016 / Accepted: 14 February 2017 / Published online: 3 March 2017

(C) The Author(s) 2017. This article is published with open access at Springerlink.com

\begin{abstract}
A geomechanical model can reveal the mechanical behavior of rocks and be used to manage the reservoir programs in a better mode. Fluid pressure will be reduced during hydrocarbon production from a reservoir. This reduction of pressure will increase the effective stress due to overburden sediments and will cause porous media compaction and surface subsidence. In some oil fields, the compacting reservoir can support oil and gas production. However, the phenomena can also cause the loss of wells and reduced production and also cause irreparable damage to the surface structures and affect the surrounding environment. For a detailed study of the geomechanical behavior of a hydrocarbon field, a 3D numerical model to describe the reservoir geomechanical characteristics is essential. During this study, using available data and information, a coupled fluid flow-geomechanic model of Fahlian reservoir formation in X-field in SW of Iran was constructed to estimate the amount of land subsidence. According to the prepared model, in this field, the maximum amount of the vertical stress is $110 \mathrm{MPa}$ and the maximum amount of the horizontal stress is $94 \mathrm{MPa}$. At last, this model is used for the prediction of reservoir compaction and subsidence of the surface. The maximum value of estimated ground subsidence in the study equals
\end{abstract}

Hossein Hassani

hhassani@aut.ac.ir

1 Department of Petroleum Engineering, Amirkabir University of Technology, Tehran, Iran

2 Mine Exploration Engineering, Amirkabir University of Technology, Tehran, Iran

3 Mining and Rock Mechanics, Amirkabir University of Technology, Tehran, Iran to $29 \mathrm{~mm}$. It is considered that according to the obtained values of horizontal and vertical movement in the wall of different wells, those movements are not problematic for casing and well production and also the surrounding environment.

Keywords Mechanical earth model $\cdot$ Coupled fluid flow-geomechanic model $\cdot$ Surface subsidence $\cdot$ Hydrocarbon reservoir compaction

\section{Introduction}

Reservoir compaction is usually dealt with surface subsidence or operational problems. Some well-known cases include the Willmington field in California and the Ekofisk field in the North Sea. Depletion of the Willmington field caused a subsidence bowl reaching a maximum depth of $9 \mathrm{~m}$ (Mayuga 1970; Kovach 1974). The sea floor under the Ekofisk platform sank by 1984 in excess of $3.5 \mathrm{~m}$, and the platform had to be extended (jacked up) at a cost of US \$1 billion (Sulak 1991). Compaction is present in many other North Sea chalk reservoirs such as Ekofisk, Valhall, Dan, Tyra, and Gorm. Another example is the Groningen gas field in the Northern part of the Netherlands in which the fault reactivation resulted in the seismic activity, well failure and casing deformations (Houtenbos 2000). Recent exploration activity tends to discover more and more deepwater "soft" reservoirs (e.g., in the Gulf of Mexico) and hightemperature/high-pressure reservoirs, where compaction is often an important issue (Settari 2002).

Compaction of the reservoir itself, besides providing the additional drive energy for production (in some cases amounting 50 to $80 \%$ of total energy), has important 
consequences both inside and outside the reservoir. The most obvious of them is the surface/seafloor deformation (i.e., subsidence), which causes the loss of wells and reduced production and also causes irreparable damage to the surface structures and the surrounding environment. From an engineering perspective, an inaccurate estimate of the compaction effect can lead to over- or underestimation of reserves, even in the gas reservoirs (Settari 2002).

In this paper, the process of making a coupled fluid flow-geomechanic model of Fahlian reservoir formation by using available data and information has been proposed. After that, the model is used to estimate the geomechanical parameters such as effective stress and the amount of land subsidence in the X-oil field.

\section{Study area}

$\mathrm{X}$-field is located in the south-east of Iran. This field is an N-E oriented anticline. X-field is $23 \mathrm{~km}$ long and $9 \mathrm{~km}$ wide. Fahlian is the main reservoir formation of this field. This formation is widespread in the southwest of Iran and not only in X-field but also in other south western fields of Iran such as Khorramshahr (400 m thick), Omid, Mansouri, and Ahvaz; it is known as a hydrocarbon reservoir formation. Figure 1 shows the stratigraphic cross section of the formations in the $\mathrm{X}$ field.

In this study, data from 31 wells located in the field (4 gas injection wells, 1 groundwater monitoring well and 26 production wells) were used. Moreover, the following data were also used:

- The primary dynamic model (fluid flow model) of the reservoir in which layer number and general form of reservoir were specified

- Underground contour (UGC) maps of all layers and sublayers of the reservoir

- Drilling report of all wells

- Well completion report of all wells

- Field development plan report

- Formation evaluation reports of some wells
Fig. 1 Stratigraphic column of $\mathrm{X}$-field

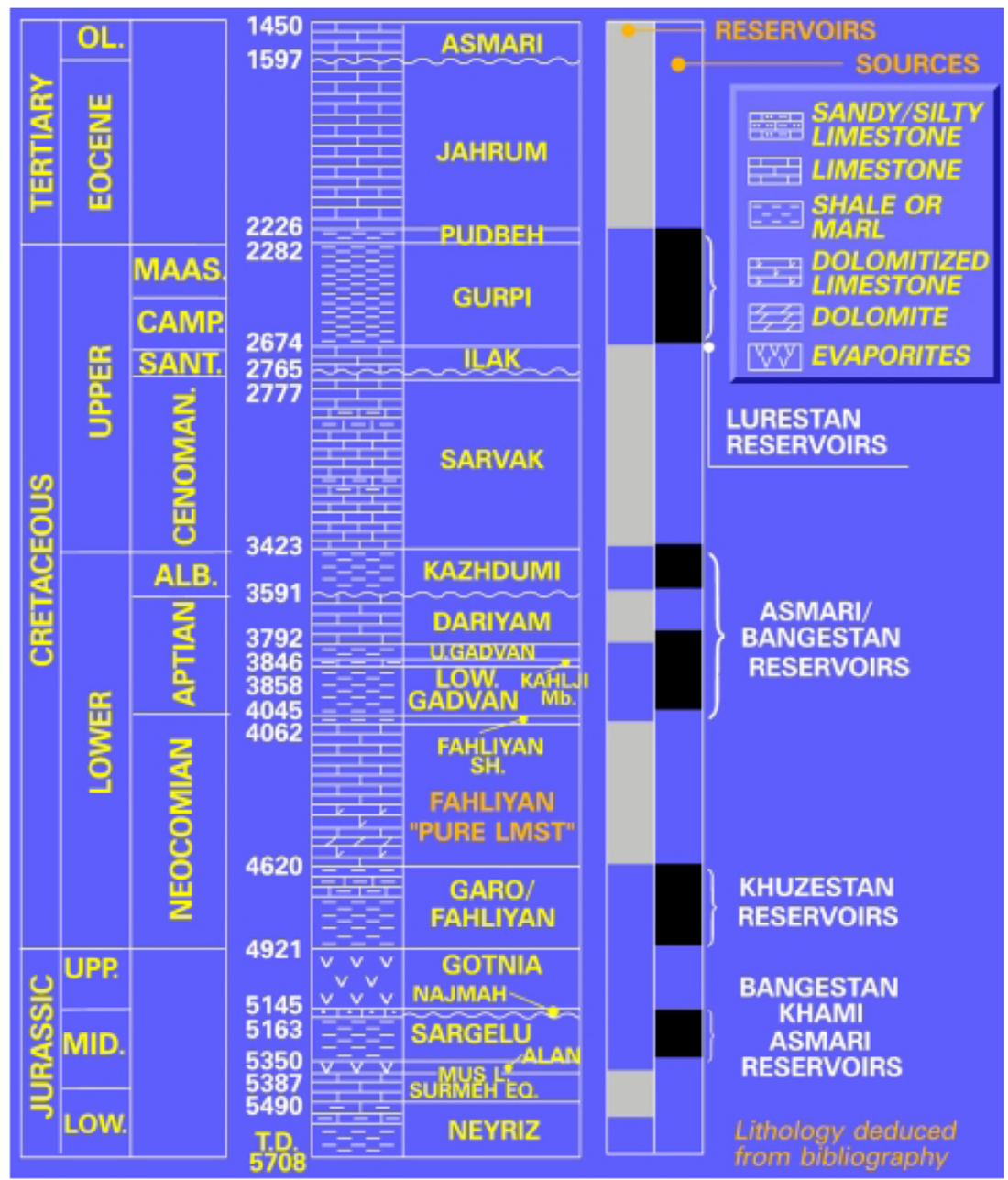


- Routine and Special Core Analysis data (porosity, permeability, fluid saturation, relative permeability, compressibility of rock)

- Pore pressure distribution data in the entire reservoir

\section{Static modeling}

Based on the pattern distribution of important petrophysical parameters, and also the availability of underground contour maps for 27 horizons of the reservoir, static model was made. The generated gridding system includes 38 cells along the $x$-axis and 83 cells along the $y$-axis. $Y$-axis with an azimuth of $5^{\circ}$ has been rotated due to getting parallel to elongation major axis of fold. In the middle section of the field, in which changes in all parameters are more important, cell size has been decreased relative to adjacent cells (with proportion of 0.5 ). The middle cell size is considered $250 \times 250 \mathrm{~m}$. In other parts of the region, in which discretization is less important, cells are grouped for a decreasing number of cells and

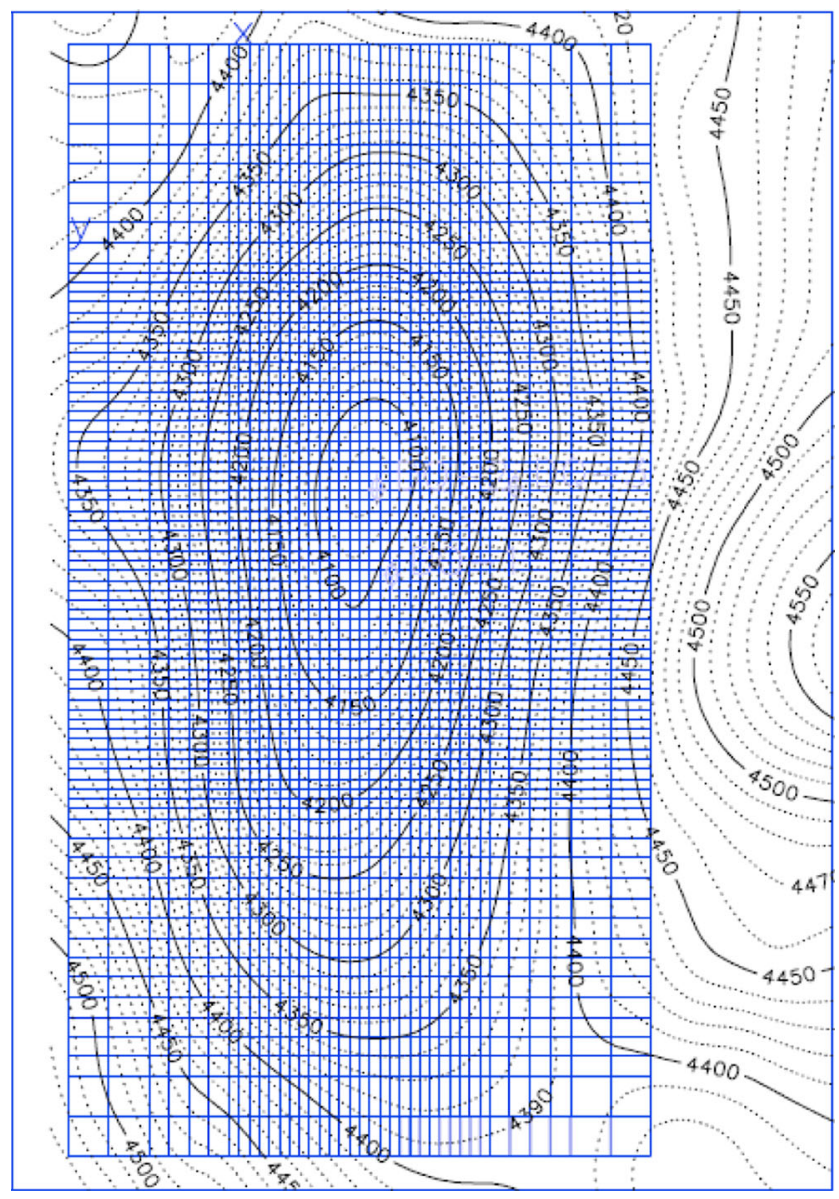

Fig. 2 Reservoir gridding system ( $x$ - and $y$-axes) the edge effect. Dimensions of this group are $250 \times 300$ or $1000 \times 1000 \mathrm{~m}$. The designed networking system for the field is illustrated in Figs. 2 and 3. Finally, the reservoir construction model is generated with 267,260 $(83 \times 115 \times 28)$ cells. According to the field data, there is no fault in this part of the field.

\section{D modeling of reservoir characteristics}

For modeling the properties such as effective porosity, absolute permeability, water saturation, and so on, well logging data related to those properties in all wells, which were calibrated using core data, are used. It is necessary to note that effective porosity and permeability of each well were gained using core tests data. Actually, in this study, these data were available in the corrected mode.

The Sequential Gaussian Simulation (SGS) method is used for 3D reservoir characteristics modeling. For an extensive review of other geostatistic methods, see de Almeida (2010). Actually, among different methods for propagating properties in three dimensions, we choose this method because this Variogram-based method is superior to other methods in geoestatistic simulation of the reservoir rock properties.

\section{Geomechanical modeling}

At the beginning of 3D geomechanical modeling, onedimensional mechanical earth models (1D MEM) were

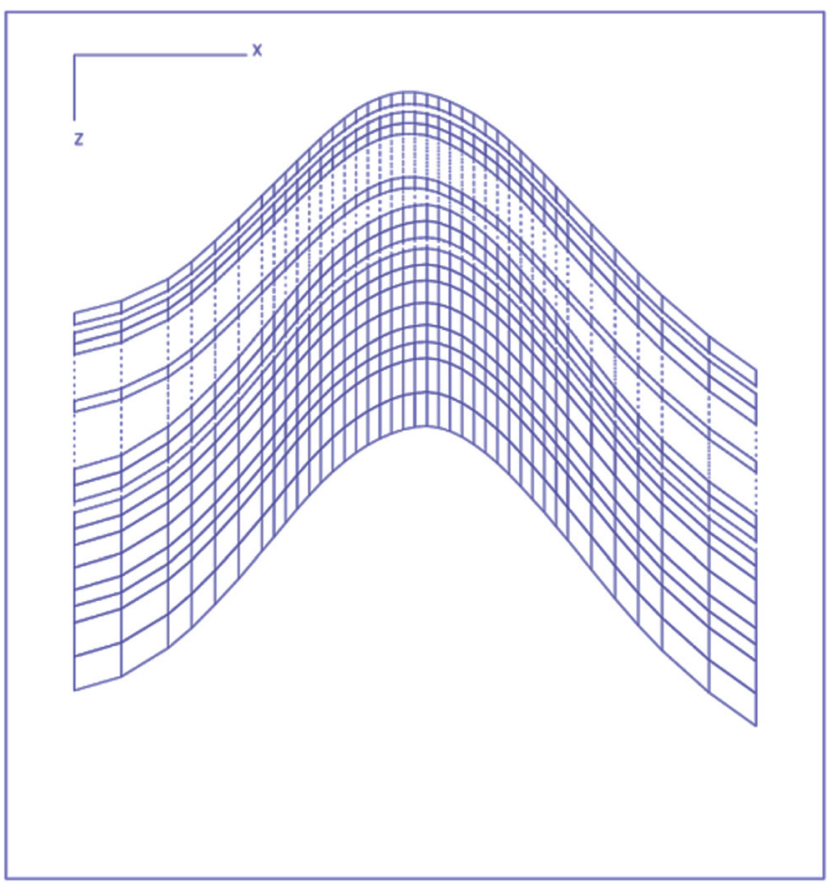

Fig. 3 Reservoir gridding system ( $x$ - and $z$-axes) 


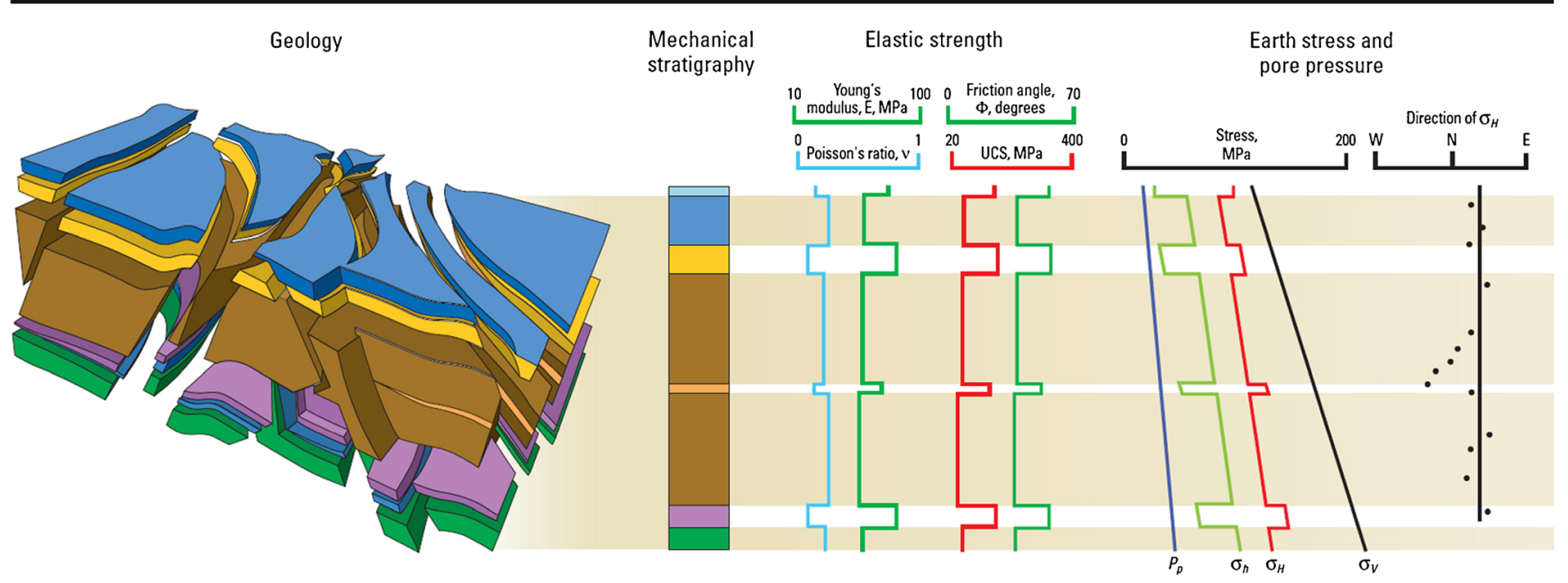

Fig. 4 Representation of 1D geomechanical model (Ali et al. 2003)

Fig. 5 Safe mud window and different instability thresholds (Fjar et al. 2008)
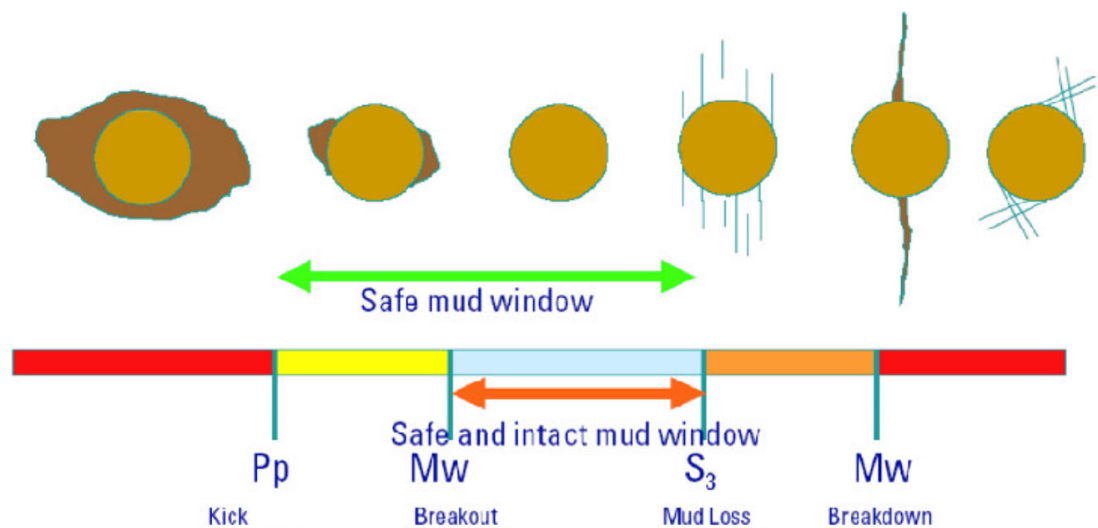

$\mathrm{Pp}$

Mud Weight

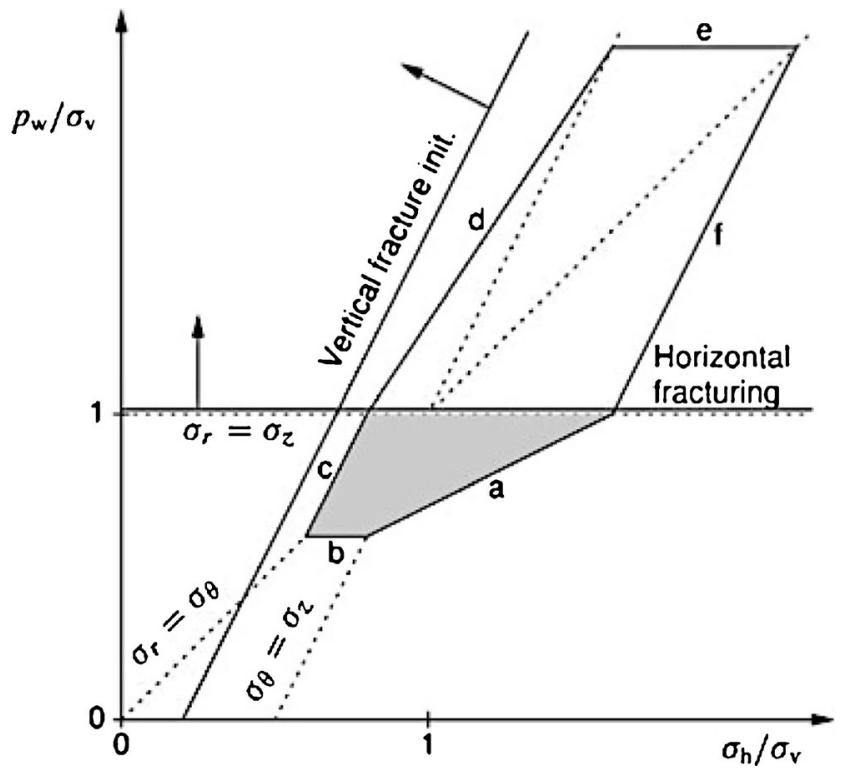

Fig. 6 Graphical representation of conditions for borehole failure for a simplified condition. The Mohr-Coulomb failure criterion with $\mathrm{UCS}=0$, $p f=0.4 \sigma_{v}$ and $\tan ^{2} \beta=3$ is assumed. The polygon will grow in all directions if UCS is nonzero (Fjar et al. 2008) built for 10 wells located in the field and then, the mentioned models were used in Finite element code in order to build the 3D geomechanical model. After that, to examine the influence of the production/injection-induced pressure changes, the three-dimensional finite difference reservoir simulations were input into three-dimensional finite element geomechanical simulations (Teatini et al. 2014).

\section{D geomechanical model}

One-dimensional geomechanical model is constructed based on drilled well data and along that well. This model investigates the mechanical effects of rocks in wellbore, and it studies around the well and also others effects such as breakouts, loss, sand production, and wellbore stability. This model is built for a well based on well log data such as wave velocity (shear and compression waves), density, caliper, porosity, and gamma ray and used to represent mechanical properties and stress states near wellbore (Ali et al. 2003). The built model also used to predict 
Fig. 7 a Conditions of main stresses, b stability threshold limits of well according to Fjar equations, and $\mathbf{c}$ an example of appropriate fitting of designed geomechanical model and FMI data (well no. 10)

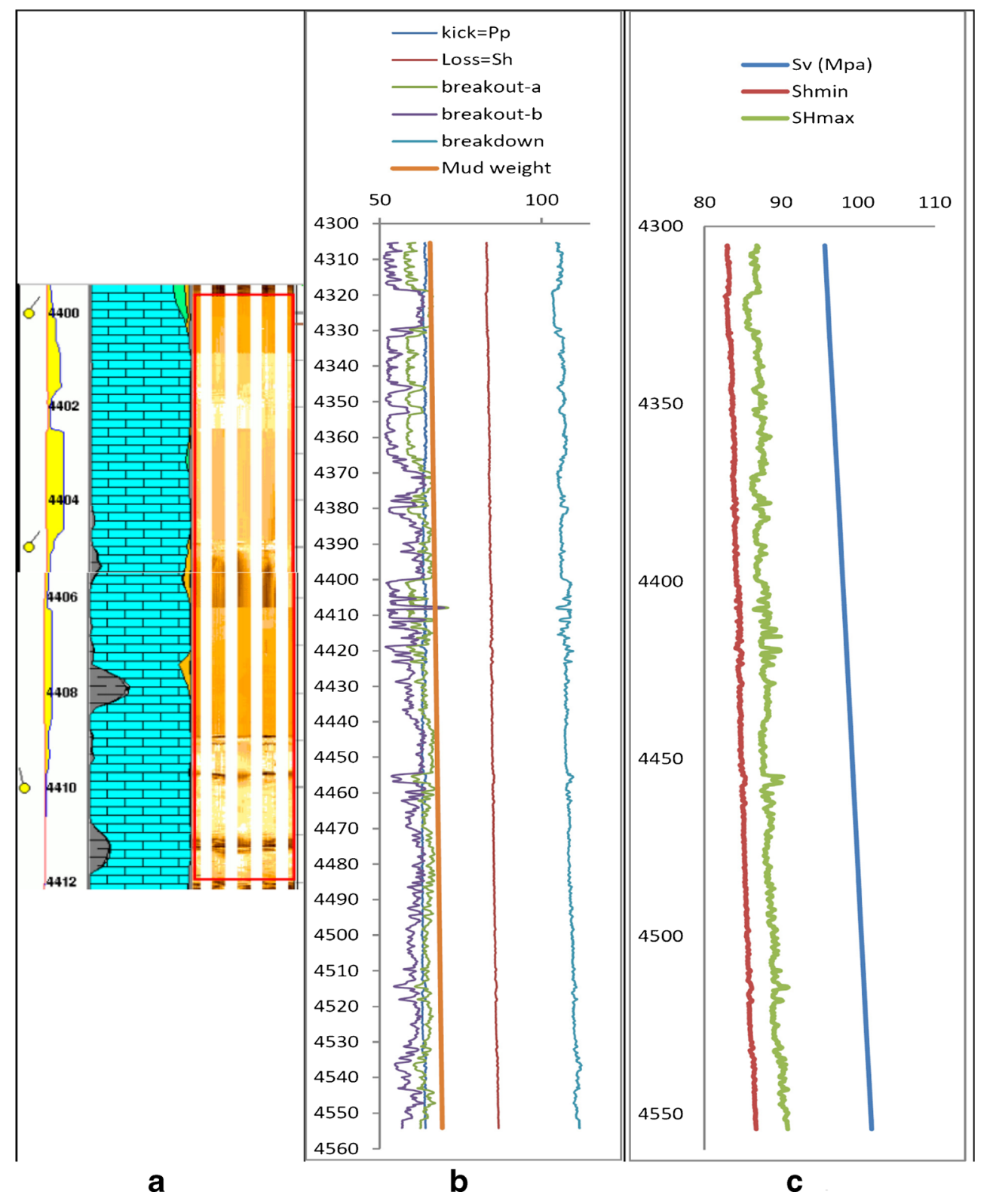

optimal mud weight window, stability of future wells, and well trajectories (Himmerlberg and Eckert 2013). Among the parameters that are represented include elastic parameters (young, bulk and shear modulus, Poisson's ratio), strength parameters (UCS, ${ }^{1}$ tensile strength, internal friction angel, cohesion), stresses (vertical, maximum and minimum horizontal stresses), and pore pressure. An example of a 1D geomechanical model is shown in Fig. 4.

In this study, data from shear and compressional wave velocity and also rock mechanical tests were used to determine elastic parameters such as Young, shear and bulk modulus, Poisson ratio, cohesion, angle of internal friction, and

\footnotetext{
${ }^{1}$ Unconfined Compressive Strength
}

unconfined compressive strength (UCS) for reservoir formation of Fahlian. Then, for stress condition analysis, due to the lack of stress measurement in the studied area, stress condition was determined based on theories and assumptions related to wells. Lithostatic pressure (vertical stress) is the pressure which is applied by the upper layers and their weights to the lower ones. Overburden pressure in the depth of $z$ is determined using the equation below:

$P(z)=P_{0}+g \int_{0}^{z} \rho(z) \mathrm{d} z$

In which, $\rho(z)$ is the density of overburden rocks in the depth of $z$, and $g$ is the earth acceleration. $P_{0}$ is the base pressure (like pressure on the surface) (D.zobak 2007). The 


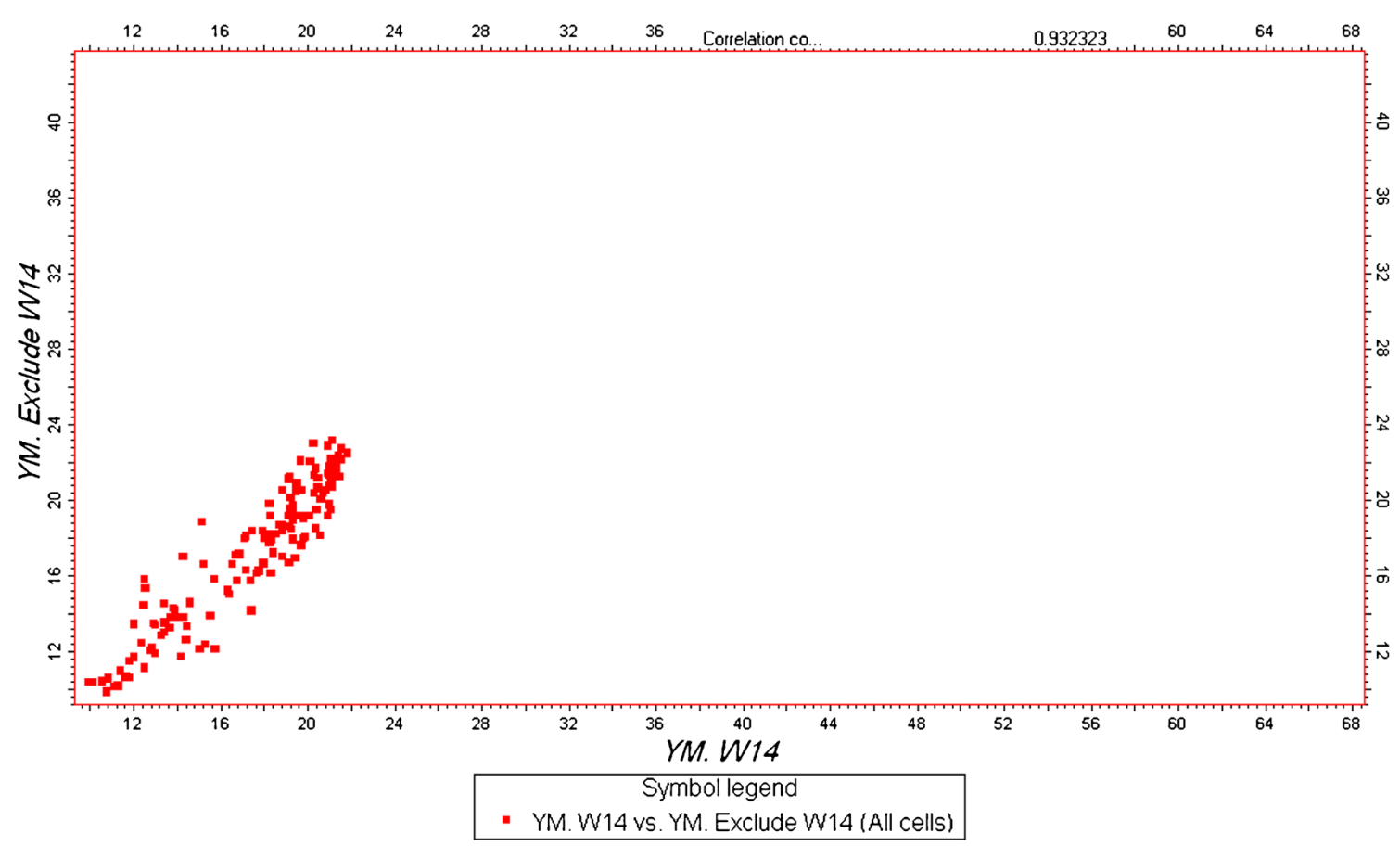

Fig. 8 Comparison of modeled Young's modulus with real data from well\#14

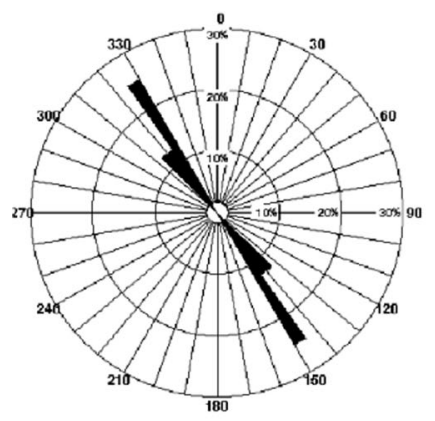

a Well\#6

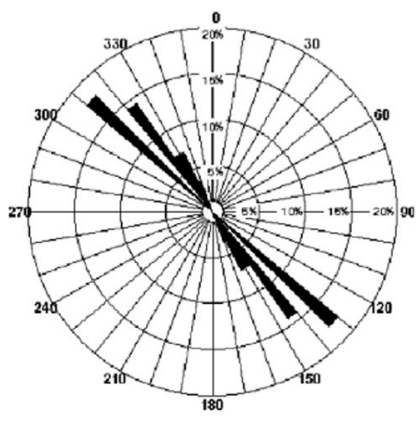

b Well\#5

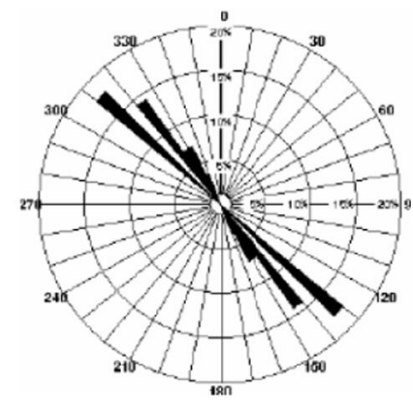

C Well\#10
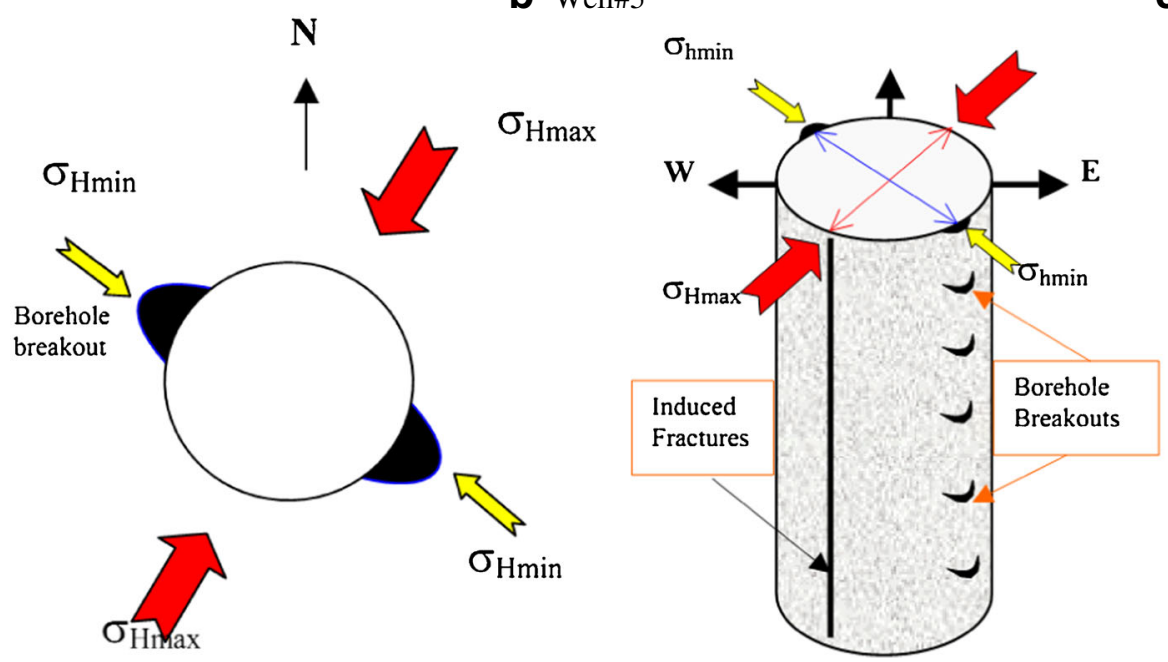

d

Fig. 9 a-c Fracture orientations in well numbers 6, 5, and 10, respectively. d Determining direction of horizontal stresses from well fracture orientations 


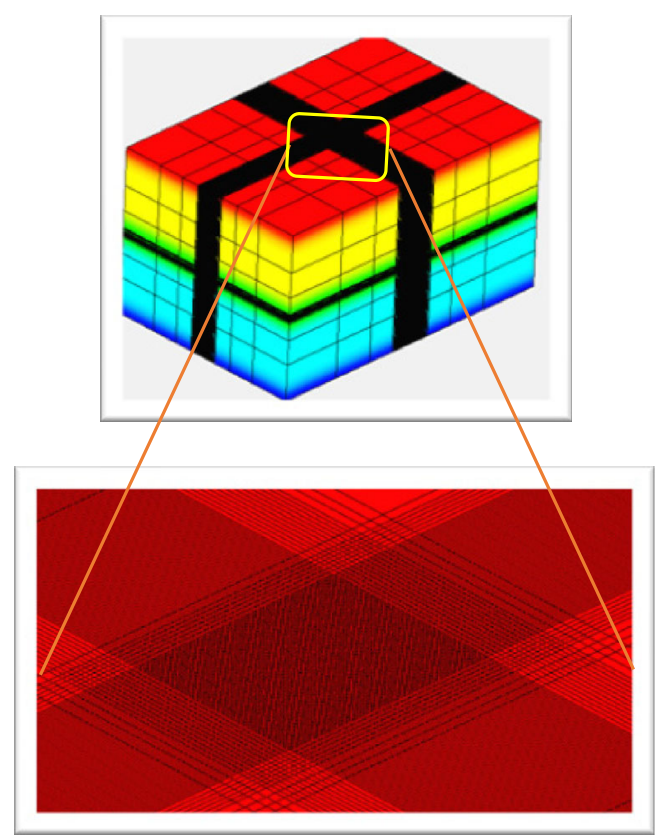

Fig. 10 Geomechanical model networking for iterative combined simulation

vertical stress profile is specified based on the density of layers (Fig. 7). Knowing about the stress regime ruling, the studied area is very important; therefore, appropriate and accurate equations can be chosen and accurate interpretations can be presented (Herwanger 2014). Overall, accurate information is not available about the stress regime ruling the Fahlian reservoir area; thus, different proportions of horizontal over vertical

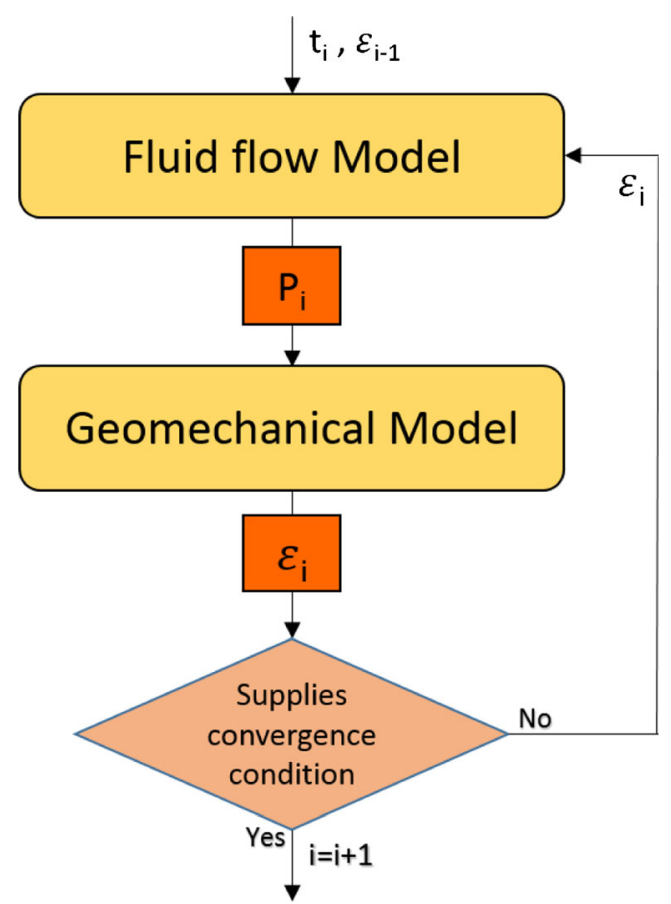

Fig. 11 Iteratively coupling strategy between fluid flow and geomechanical models stress are considered, and according to information obtained from drilling, the best value was selected.

\section{Stress condition analysis}

As the most conventional condition, the regime of the area has been considered as normal and horizontal stress was calculated based on the following equation:

$K^{\prime}=\frac{\sigma^{\prime}{ }_{h}}{\sigma_{v}^{\prime}}=\frac{\sigma_{h}-P_{p}}{\sigma_{v}-P_{p}}$

$\sigma_{h}^{\prime}=k \sigma^{\prime}{ }_{v}=\frac{\vartheta}{1-\vartheta} \sigma_{v}$

where $k$ is the ratio between horizontal and vertical stresses, $P_{p}$ is the pore pressure, and $\vartheta$ is the Poisson ratio (D.zobak 2007). In order to evaluate the resulted stress state, instability threshold (usually called: kick, breakout, loss, and break down) should be calculated, and applied mud weight should be compared with those thresholds (Fig. 5).

Among those thresholds, breakout is related to the shear failure around the borehole. A method for the determination of shear failure around boreholes was outlined by Fjar et al. (2008), which was based on the work by Guenot and Santarelli (1988). This method proposes a set of criteria, which forms a polygon (Fig. 6). This method is also applied in the current study.

Applying the abovementioned method for different ratio of horizontal to vertical stress led to various results. It seems that choosing the exact ratio between horizontal and vertical stress is essential for the determination of possible failure around the borehole for different mud weights. Comparing the results with the drilling report can be used as a validation method for proposed stress regime. As mentioned before, there is not any stress measurement records in the area. In order to study the different possible stress states, different failure thresholds were calculated for a range of ratios of horizontal to vertical stresses. According to drilling reports and image logs, noticeable failures and instabilities of the ratio of horizontal to vertical stress were assumed to be 0.6 , stress regime should be normal, and vertical wells should be the most stable ones. After that, we can determine the proportion of strains along the $x$ - and $y$-axis using Eq. 2 and the maximum horizontal stress based on Eq. 3.

$$
\begin{gathered}
\sigma_{h}=\frac{\vartheta}{1-\vartheta} \sigma_{v}+\frac{1-2 \vartheta}{1-\vartheta} \alpha P_{p}+\frac{E}{1-\vartheta^{2}} \varepsilon_{x}+\frac{\vartheta E}{1-\vartheta^{2}} \varepsilon_{y} \\
\sigma_{H}=\frac{\vartheta}{1-\vartheta} \sigma_{v}+\frac{1-2 \vartheta}{1-\vartheta} \alpha P_{p}+\frac{E}{1-\vartheta^{2}} \varepsilon_{y}+\frac{\vartheta E}{1-\vartheta^{2}} \varepsilon_{x}
\end{gathered}
$$

In which, $P_{p}$ is the pore pressure and $\vartheta$ is the Poisson's ratio (D.zobak 2007).

So, we have one-dimensional geomechanical model for each well (Fig. 7 shows this model for well \#10 of field). 


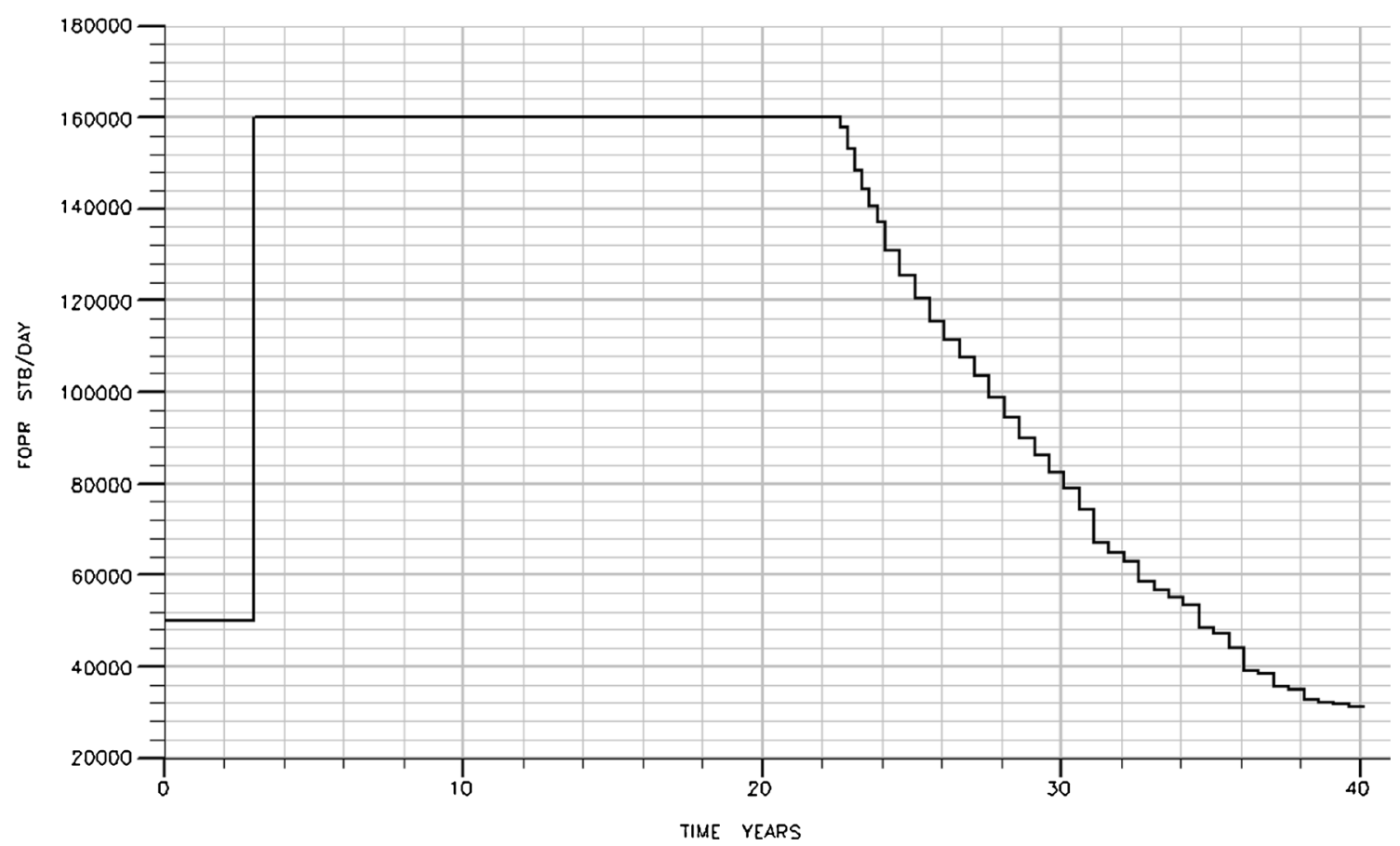

Fig. 12 Oil production rate from Darkhovin field

\section{D geomechanical parameters model}

Geomechanical parameters modeling such as Poisson's ratio, Young, shear and bulk modulus, and also unconfined compressive strength should be carried out for $3 \mathrm{D}$ geomechanical modeling (Ouellet et al. 2011). As described in "1D geomechanical model" section, we made 1D mechanical earth model for 10 wells. Similar to 3D porosity and permeability modeling, the sequential Gaussian simulation method is also used for modeling

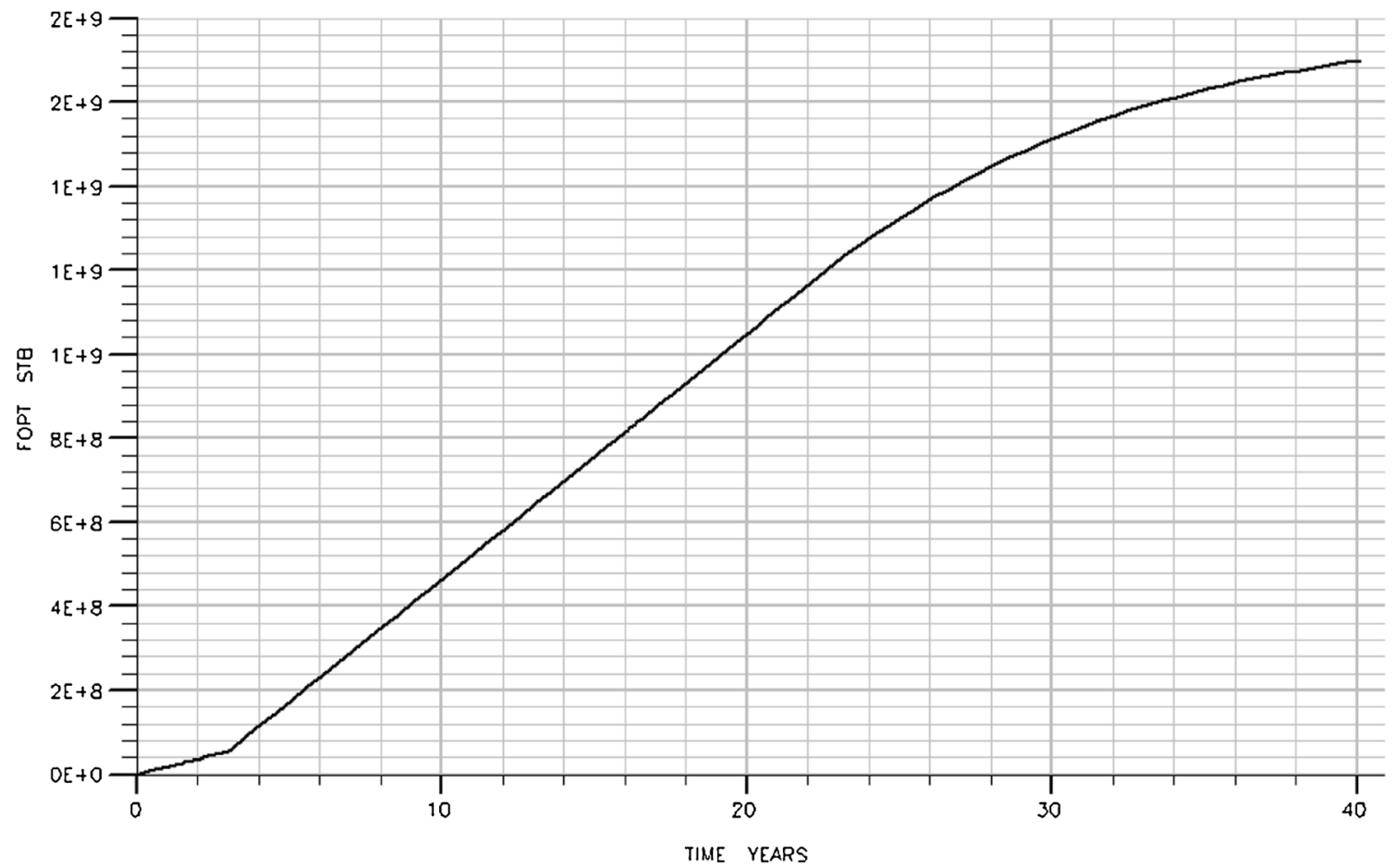

Fig. 13 Cumulative value of oil production in Darkhovin field 
of the mentioned parameters in $3 \mathrm{D}$ space. That is why for each parameter, variography is carried out separately and also appropriate distribution functions have been specified for them.

In this study, the 3D geomechanical model has been built based on data from 10 wells. An example of this comparison between the modeled Young's modulus and real data in well no. 14 is presented in Fig. 8. It is necessary to note that according to the direction of fractures in field wells, the minimum horizontal stress direction is considered at NW-SE (Fig. 9).

\section{Iteratively coupled fluid flow and geomechanics}

\section{Field production scenario}

According to the available reports from X-field, two phases have been considered for oil production and gas injection in the development of the field. In the first phase, wells no. 1 to 11 started producing oil from the reservoir from December 31, 2003, to December 31, 2006.After that, the second phase of production with gas injection was initiated. In the second phase, gas injection to the reservoir by wells no. 19, 21, 23, and 23 was initiated. In that phase, oil was produced from other wells except for well no. 28 which was a monitoring well for the groundwater aquifer.

\section{D model preparation}

After running the reservoir fluid flow simulation, the output related to the reservoir model was used as a text file input for the geomechanic code, and then the code was run for geomechanical stress and strain analysis. In the second coded application, which handles stress analysis and subsidence estimation of the ground, reservoir gridding cells were considered greater than the primary state for preventing edge effect on geomechanical simulation (Ouellet et al. 2011). Therefore, reservoir networking in three directions of $x, y$, and $z$ has been increased 1.5 times (Fig. 10).

Likewise, in the geomechanical model, gridding cells have been continued from the top of the model to the ground surface (which considers flat here) and from the bottom of the model to the basement which is uncompressible.

\section{Boundary conditions and stresses}

The four lateral edges of the geomechanical model were free to displace in all directions. The bottom of the model was fixed, whereas the top (i.e., earth surface) was free to displace in all directions. The prescribed tectonic stress state around reservoir has a significant impact on the numerical results because of the non-linearity of the material models. Vertical stress due to gravitational loading

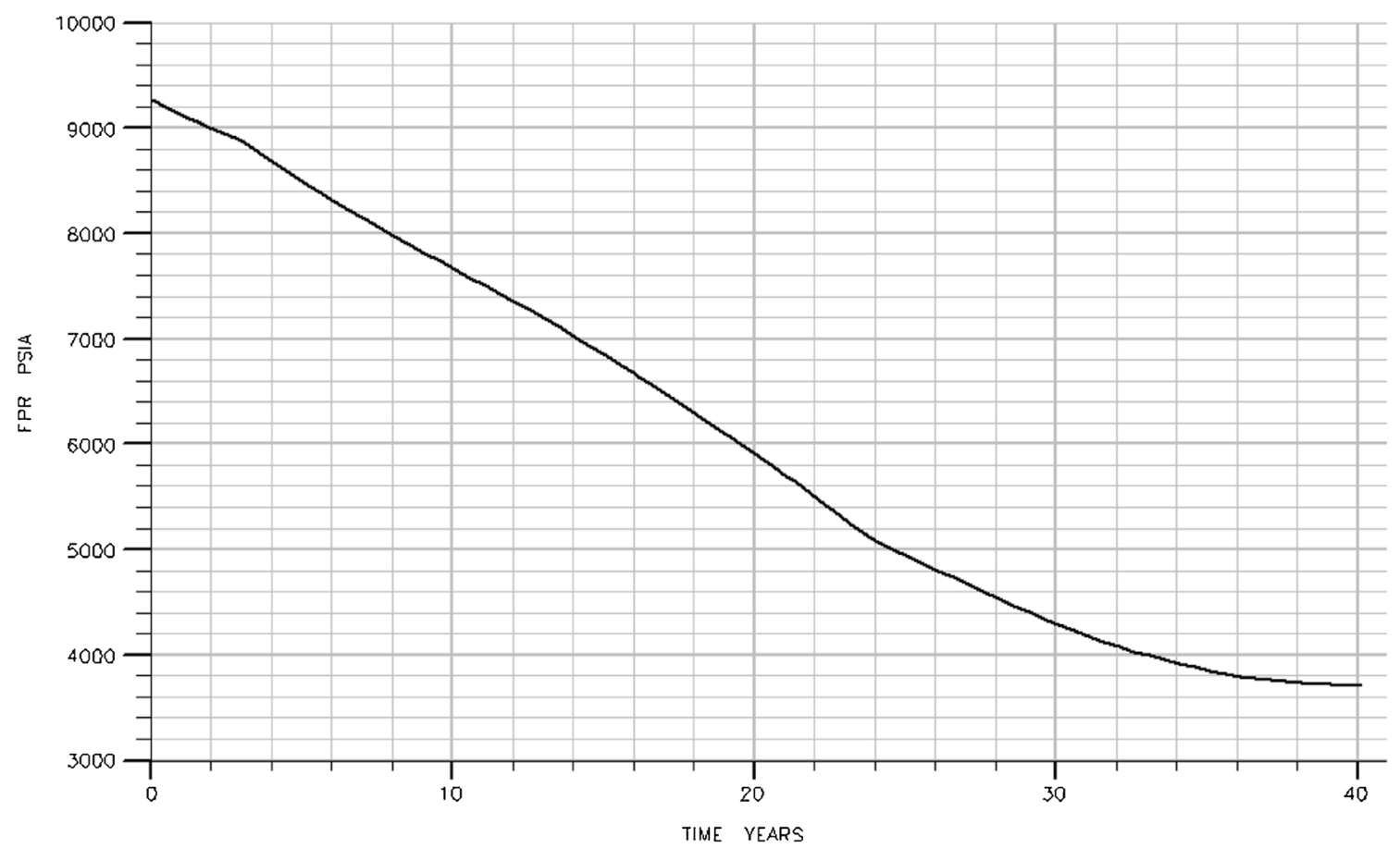

Fig. 14 Average reservoir pressure 


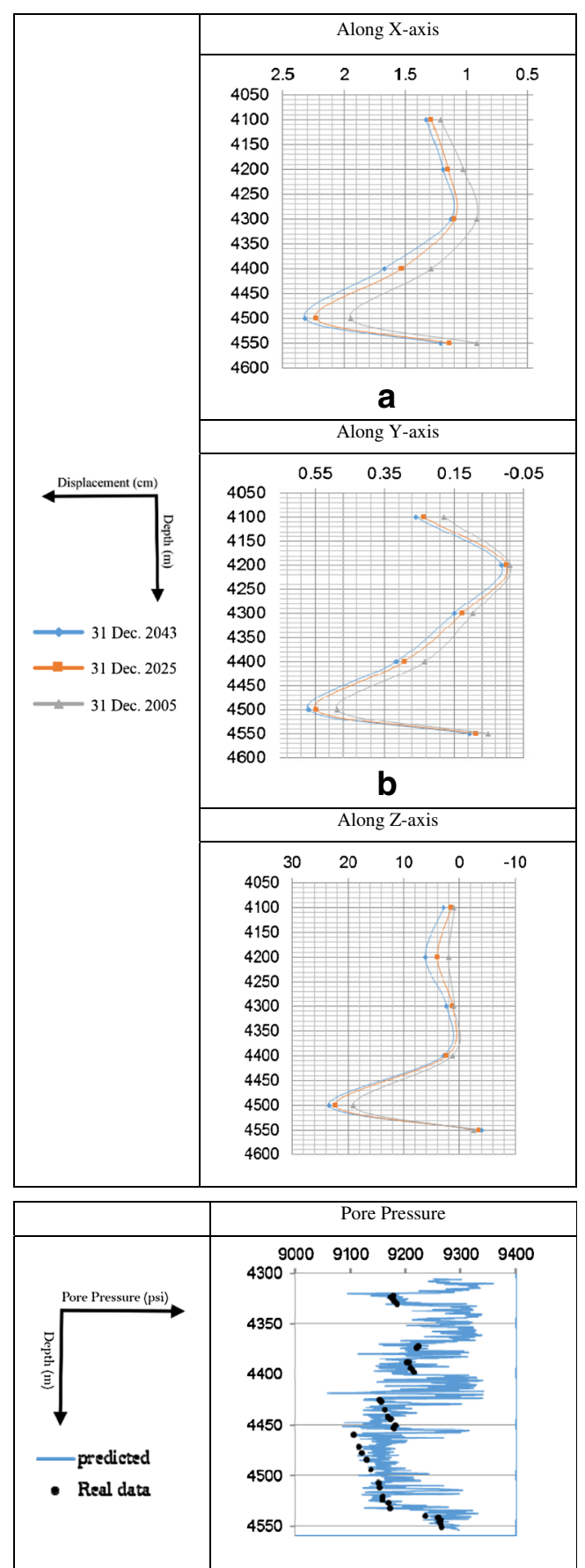

Fig. 15 a-c Horizontal elastic movement on wall of well no. 10 along $x$-, $y$-, and $z$-axis, respectively. $\mathbf{d}$ Estimated vertical profile of pore pressure in well no. 10 based on observed data

was calculated directly from the bulk density of the overlying materials with initial pore pressures in the different stratigraphic layers calculated as described, and also the two horizontal (principal) effective stresses, which are oriented parallel to the model boundaries, were previously computed at each node.

\section{Coupled model results}

Fluid flow simulation in the field has been considered in two phases, and the model execution time interval is 1 month. The considered simulation running time is 40 years. Thus, the last model execution time will be December 2043. According to the selected iterative approach for the combined simulation of the geomechanical model and fluid flow model, December 31, 2005, 2025, and 2043 have been considered for the geomechanical analysis of surface subsidence estimation. Actually, in the mentioned dates, output of the reservoir simulation model will be imported to the geomechanical model as an input data, and after some analyses, geomechanical outputs, which are a new amount of reservoir permeability and porosity, will again be imported to the reservoir simulation model for calculating the new pore pressure in the next time step and also fluid flow continuation. Figure 11 schematically shows linking geomechanical model and fluid flow model for iteratively coupled simulation.

Figures 12 and 13 show the field oil production rate and its cumulative value, respectively. In Fig. 14, the average pore pressure changes of the field are presented over 40 years.

The databases for the geomechanical simulations consist of the nodal displacements as a function of time. Two aspects of the simulations are of particular interest: vertical compaction at the top of the model (surface subsidence) and nodal displacements (well deformations). Figure 15a shows horizontal elastic movement along the $x$-axis on the wall of well no. 10 for several different time steps in which horizontal axis is movement and vertical axis is the depth of the observed point on the wall of the well. Similarly, Fig. $15 \mathrm{~b}$ shows a similar state of the previous diagram for well no. 10 along $y$-axis and Fig. 15c also presents such a state for well no. 10 along the longitudinal axis of the well, i.e., $z$-axis.

As the diagrams show, horizontal movement values are significantly less than the same values along the longitudinal axis of the well. Thus, in designing casing of the well, casing strength along the well longitudinal axis is more important. In Fig. 15a, b, horizontal movement changes, at a specific depth for several time periods, are few and horizontal movement value for middle horizons of the reservoir is less.

According to the above figures and Fig. 15d which show the pore pressure data for well no. 10, it is clear that by fluid pore pressure reduction, movement increases, and by its increase, movement becomes less. Also, in Fig. 15c, except for the deepest reservoir horizon points that come along with reservoir expansion, subsidence is observed in other upper points of the reservoir 
Fig. 16 Cross section of maximum ground subsidence in $y=977,200$

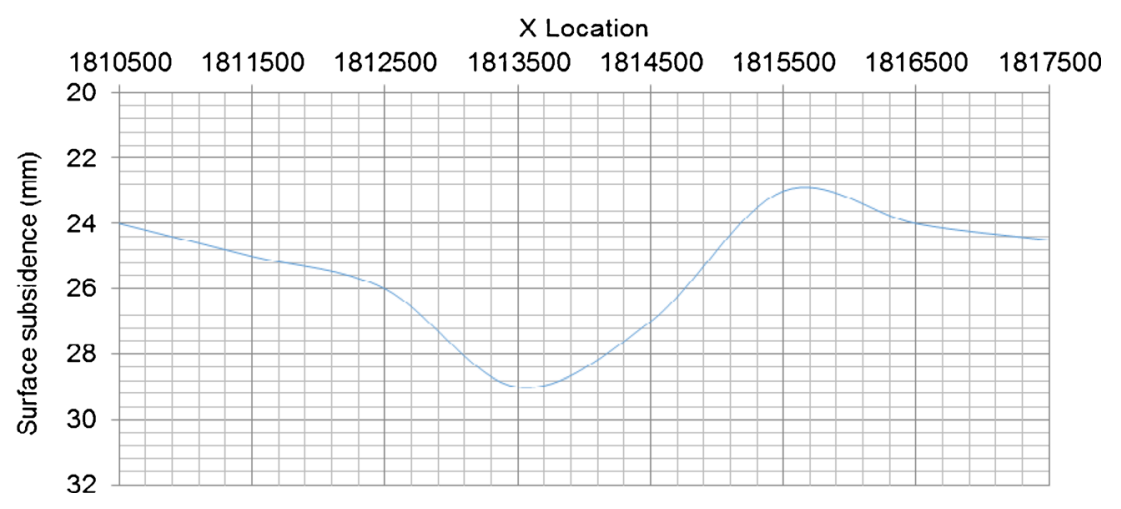

which is due to gas injection in the lower layers of the reservoir.

Figure 16 shows the cross section of the maximum ground surface subsidence at the top of the reservoir in which subsidence value has increased by approaching the top of the reservoir and vice versa. Figure 17 also shows a similar state for the longitudinal profile of the maximum ground surface subsidence. It is observed that ground subsidence in the study is insignificant and maximum value equals $29 \mathrm{~mm}$. The reason considered can be gas injection scenario beside oil production from the reservoir because gas injection can somewhat prevent reservoir compactness and ground subsidence. It is considered that according to the obtained values of horizontal and vertical movement in the wall of different wells, those movements are not problematic for casing and well production and also the surrounding environment.

\section{Conclusions}

Three-dimensional finite element mechanical simulations reveal the evolution of the subsurface stress and displacement fields in the reservoir and overburden, and show how local production and injection patterns affect their spatial and temporal variation. In this study, the geomechanical simulations are performed for Fahlian reservoir formation in one of the oil fields in SW of Iran. Magnitude and direction of the stress field were calculated based on available data such as geological, geomechanical, geophysical, and reservoir engineering data. According to the constructed model, the maximum amount of vertical and horizontal stresses is 110 and $94 \mathrm{MPa}$, respectively. However, the 3D Sequential Gaussian Simulation (SGS) method is used for 3D reservoir characteristics modeling. This method shows about $90 \%$ correlation between real data and model data of rock mechanics parameters such as shear or young modulus. From iteratively coupled fluid flowgeomechanics provided, model observed that ground subsidence in the study is insignificant and the maximum value equals $29 \mathrm{~mm}$. The reason considered can be the gas injection scenario beside oil production from the reservoir because gas injection can somewhat mitigate reservoir compaction and surface subsidence. According to the obtained values of horizontal and vertical displacement in the wall of different wells,
Fig. 17 Longitudinal profile of maximum ground subsidence in $x=1,814,000$

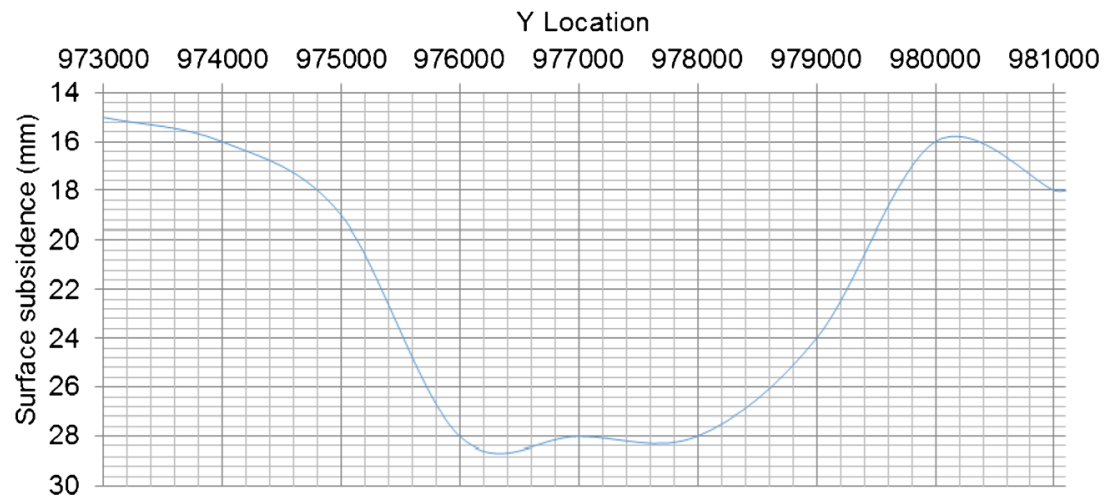


those are not problematic for casing and well production and also the surrounding environment.

Open Access This article is distributed under the terms of the Creative Commons Attribution 4.0 International License (http:// creativecommons.org/licenses/by/4.0/), which permits unrestricted use, distribution, and reproduction in any medium, provided you give appropriate credit to the original author(s) and the source, provide a link to the Creative Commons license, and indicate if changes were made.

\section{References}

Ali AHA, Brown T, Delgado R, Lee D, Plumb D, Smirnov N, Marsden R, Prado-Velarde E, Ramsey L, Spooner D (2003) Watching rocks change - mechanical earth modeling. Oilfield Review 15(1):22-39

D.zobak M (2007) Reservoir geomechanics. Cambridge University press

de Almeida JA (2010) Stochastic simulation methods for characterization of lithoclasses in carbonate reservoirs. Earth Sci Rev 101(3):250 270

Fjar E, Holt RM, Raaen A, Risnes R, Horsrud P (2008) Petroleum related rock mechanics, Elsevier

Guenot A, Santarelli F (1988) Borehole stability: a new challenge for an old problem. The 29th US Symposium on Rock Mechanics (USRMS), American Rock Mechanics Association
Herwanger J (2014) Seismic geomechanics: how to build and calibrate geomechanical models using 3D and 4D seismic data. Education Days Stavanger 2014

Himmerlberg N, Eckert A (2013) Wellbore Trajectory Planning for Complex Stress States. 47th US Rock Mechanics/Geomechanics Symposium, American Rock Mechanics Association

Houtenbos A (2000) The quantification of subsidence due to gasextraction in the Netherlands. Land Subsidence, proceedings of the IAHS Sixth International Symposium On Land Subsidence (SISOLS)

Kovach RL (1974) Source mechanisms for Wilmington oil field, California, subsidence earthquakes. Bull Seismol Soc Am 64(3-1): 699-711

Mayuga M (1970) Geology and development of California's giantWilmington oil field

Ouellet A, Bérard T, Desroches J, Frykman P, Welsh P, Minton J, Pamukcu Y, Hurter S, Schmidt-Hattenberger C (2011) Reservoir geomechanics for assessing containment in $\mathrm{CO} 2$ storage: a case study at Ketzin, Germany. Energy Procedia 4:3298-3305

Settari A (2002) Reservoir compaction. J Pet Technol 54(08):62-69

Sulak R (1991) Ekofisk field: the first 20 years. J Pet Technol 43(10):1, 265-261,271

Teatini P, Castelletto N, Gambolati G (2014) 3D geomechanical modeling for $\mathrm{CO} 2$ geological storage in faulted formations. A case study in an offshore northern Adriatic reservoir, Italy. International Journal of Greenhouse Gas Control 22:63-76 